\title{
Effect That Lifestyle during the Growth Period Has on Bone Density Acquisition-Using Simple Exercise and a Nutrition Survey
}

\author{
Fumihiro Omasu ${ }^{1}$, Misaki Umemoto ${ }^{2}$, Riko Gotanda², Tomomi Gotoh ${ }^{2}$ \\ ${ }^{1}$ Department of Health and Nutrition, Faculty of Health and Nutrition, Yamagata Prefectural Yonezawa University of Nutrition \\ Sciences, Yonezawa-shi, Japan \\ ${ }^{2}$ Department of School Health, Faculty of Education, Kumamoto University, Kumamoto-shi, Japan \\ Email: ${ }^{\star}$ omasu@yone.ac.jp
}

How to cite this paper: Omasu, F., Umemoto, M., Gotanda, R. and Gotoh, T. (2017) Effect That Lifestyle during the Growth Period Has on Bone Density Acquisition-Using Simple Exercise and a Nutrition Survey. Open Journal of Preventive Medicine, 7, 87-97.

https://doi.org/10.4236/ojpm.2017.75008

Received: April 4, 2017

Accepted: May 28, 2017

Published: May 31, 2017

Copyright $(9) 2017$ by authors and Scientific Research Publishing Inc. This work is licensed under the Creative Commons Attribution International License (CC BY 4.0).

http://creativecommons.org/licenses/by/4.0/

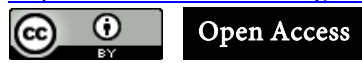

\begin{abstract}
This survey was conducted with the aim of clarifying and providing guidance regarding correct lifestyle and exercise habits from adolescence in order to prevent the development of osteoporosis. The subjects included 195 Japanese adult females. We measured their calcaneal bone density by ultrasonography, the index of which was determined as SOS (Speed of Sound). We examined their physical characteristics, health conditions, amount of physical activity, exercise history, and eating habits, and then analyzed the relationship thereof with bone density. No significant correlation was found between height, weight, BMI (Body Mass Index), or body fat percentage and the SOS value. Moreover, the bone density among those with a history of exercise was high. Breaking it down, we obtained results such as the fact that exercise habits during the junior and senior high school years had a great impact on the acquisition of peak bone mass, although no relationship between exercise habits and bone density was found during the elementary school years. Furthermore, as the bone density of students who continued exercising in junior and senior high school indicated high values, continuity of exercise during the growth period (during puberty) is believed to have a great impact on peak bone mass. Upon investigating the content of meals including foods which have a positive impact on the bones, "bean and bean products" and "green and yellow vegetables" were found to be related to bone density. From the above, the effect that the lifestyle of young adult females had on bone density was partially clarified. In particular, one factor which had a strong relationship with current bone density was exercise history during the junior and senior high school periods. It was clarified that continuously engaging in exercise and placing strain on the bones during these periods lead to high bone density acquisition.
\end{abstract}




\section{Keywords}

Ultrasound Bone Density, Young Adult Female, Exercise History, Nutrition Survey

\section{Introduction}

Bone density reaches a peak bone mass around the age of 20, and it is maintained for the following 20 to 30 years, and decreases due to increasing age after menopause. Particularly among females, menopause triggers the inhibition of osteoclast action regarding the remodeling of bones along with a reduction in estrogen secretion of female hormones which work to inhibit bone resorption, resulting in the activation of osteoclasts and decreasing bone density. Consequently, osteoporosis is significantly more prevalent in females than males.

Because a decrease in bone density after menopause is inevitable for females to one degree or another, they will experience difficulty if they enter their middle and senior years with low acquired peak bone mass. Therefore, it is believed to be important to acquire high bone density in one's youth. Recently, research studies regarding bones targeting young people have been reported [1] [2]. It has been reported that the amount of physical activity and nutritional intake in one's youth greatly affects bone density [3] [4], and that calcium intake and exercise involving applying a load to the bones is said to be important to high bone density acquisition.

Recently, the perception that being thin is beautiful has spread among young females due to the influence of magazines and mass media, leading to an increase of young females who are too thin [5]. Although most of the female's hormone estrogen is secreted from the ovaries, because substances promoting this secretion and part of estrogen are produced in the fat cells, it is surmised that for females there is a connection between being too thin and osteoporosis. Furthermore, it is said that bone strength increases by applying loads [6]. Those who are thin place smaller loads on the bones due to their light weight, meaning being light weight is surmised to cause osteoporosis.

As mentioned above, in order to prevent the development of osteoporosis particularly in middle aged and older females, a correct lifestyle, exercise habits, and weight control from adolescence are believed to be important. In this study, we conducted bone density measurements among Japanese young adult females by ultrasonography and investigated what impact the degree of obesity and lifestyle in one's youth, in particular eating habits and exercise history, has on bone density.

\section{Materials and Methods}

The subjects included a total of 195 Japanese young adult females. All data in the present study were collected in October 2015 at a university in the middle area of Kyusyu. Each of the participants lived in the area surrounding the university. 
Females with a history of treatment or therapy that might have influenced their bone mass were excluded. The study was approved by the Ethics Committee of Epidemiological Studies at Yamagata Prefectural Yonezawa University of Nutrition Sciences. All participants provided their written informed consent. The ultrasonic propagation velocity (SOS (Speed of Sound) $(\mathrm{m} / \mathrm{sec})$ ) in calcaneal bone was measured using an ultrasound bone density measuring device (CM-200 from Canon). This SOS value expresses bone strength in numerical values. Therefore, in this investigation, this SOS value was used as an index of bone density. At the time of ultrasonic propagation measurement of calcaneal bone, height and weight were also measured. Regarding lifestyle, a survey was conducted using a multiple choice questionnaire. The survey items were composed of health condition, amount of physical activity, exercise history, and eating habits. All numerical values were expressed as mean \pm standard deviation. Regarding the relationship between the SOS and physical characteristic values, a correlation coefficient was calculated. Regarding comparisons between groups, an analysis of variance was used. In all tests, the level of significance was set at $5 \%$.

\section{Results}

Table 1 indicates the physical characteristics of the 195 subjects in this study. The mean age was $20.4 \pm 2.8$ years (age range: 18 to 28 years old). Regarding the physical attributes, there was no significant difference in average Japanese adult females. The mean value of SOS was $1549.5 \pm 33.8 \mathrm{~m} / \mathrm{sec}$.

Table 2 shows the correlation between the SOS value and height, weight, BMI, and body fat percentage. The correlation coefficient between the SOS value and height was 0.02 , the correlation coefficient with weight was 0.07 , the correlation coefficient with BMI was 0.05 , and the correlation coefficient with body fat percentage was -0.11 , indicating no correlation in any case.

Table 3 shows the relationship between the presence of bone fractures or whether or not there is a family member (parent, brother or sister, grandparent) diagnosed with osteoporosis and SOS. The group having experienced bone fractures included 38 people, whereas the group with no such experience included

Table 1. Physical characteristics of the subjects.

\begin{tabular}{cc}
\hline Number of people (persons) & 195 \\
\hline Age (years) & $20.4 \pm 2.8$ \\
Height $(\mathrm{cm})$ & $157.8 \pm 5.3$ \\
Weight $(\mathrm{kg})$ & $51.1 \pm 7.1$ \\
BMI (Body Mass Index) $\left(\mathrm{kg} / \mathrm{m}^{2}\right)$ & $20.5 \pm 3.6$ \\
Body fat percentage $(\%)$ & $27.2 \pm 17.4$ \\
SOS (Speed of Sound) $(\mathrm{m} / \mathrm{sec})$ & $1549.5 \pm 33.8$ \\
\hline
\end{tabular}

Table 2. Correlation coefficients between each physical characteristic value and SOS.

\begin{tabular}{ccccc}
\hline & Height $(\mathrm{cm})$ & Weight $(\mathrm{kg})$ & BMI $\left(\mathrm{kg} / \mathrm{m}^{2}\right)$ & Body fat percentage $(\%)$ \\
\hline $\mathrm{SOS}(\mathrm{m} / \mathrm{sec})$ & 0.02 & 0.07 & 0.05 & -0.11 \\
\hline
\end{tabular}


157 people. Regarding the SOS according to the presence of bone fractures, no significant difference was observed. The group of those with a family member who had been diagnosed with osteoporosis included 17 people, whereas the group without included 178 people. Regarding the SOS according to the presence of a history of osteoporosis diagnosis in a family member, although there was a tendency for the group with the presence of a history of osteoporosis diagnosis in a family member to indicate relatively low values, it was not concluded to be a significant difference.

Table 4 shows the survey results regarding how far the subjects usually walk per day. The group who walked less than 20 minutes included 73 people, the group who walked more than 20 minutes and less than 60 minutes included 61 people, the group who walked more than 60 minutes and less than 120 minutes included 54 people, and the group who walked more than 120 minutes included 7 people. No significant difference in SOS according to the walking time was observed.

Regarding the general walking speed, Table 5 shows the survey results regarding the number of individuals to which "slowly", "natural", or "fast" applies. It was found that 28 people walk "slowly" while 36 individuals walk "fast". Regarding the SOS according to the groups divided in terms of walking speed, although there was a tendency for the "slowly" and "natural" groups to indicate relatively low values, it was not concluded to be a significant difference.

Table 6 shows the survey results in terms of whether they do some form of exercise such as walking, jogging, and cycling or work or labor which increases their heart rate or leaves them out of breath at least once a week. The group of people who currently engage in some form of exercise or work more than once a week included 72 people, while the group who do not included 123 people.

Table 3. SOS values according to the presence of bone fracture experience and the presence of a family member who was diagnosed with osteoporosis.

\begin{tabular}{ccc}
\hline & Presence & Absence \\
\hline Bone fracture experience & 38 people & 157 people \\
& $1557.0 \pm 42.8$ & $1547.3 \pm 31.3$ \\
A family member (parent, brother or sister, & 17 people & 178 people \\
grandparent) who was diagnosed with osteoporosis & $1543.8 \pm 37.3$ & $1549.9 \pm 33.5$ \\
\hline
\end{tabular}

Table 4. SOS values according to usual walking time per day.

\begin{tabular}{|c|c|c|c|c|}
\hline & $\begin{array}{c}\text { Less than } 20 \\
\text { minutes }\end{array}$ & $\begin{array}{c}\text { More than } 20 \text { minutes and } \\
\text { less than } 60 \text { minutes }\end{array}$ & $\begin{array}{c}\text { More than } 60 \text { minutes and } \\
\text { less than } 120 \text { minutes }\end{array}$ & $\begin{array}{c}\text { More than } 120 \\
\text { minutes }\end{array}$ \\
\hline SOS & 73 people & 61 people & 54 people & 7 people \\
\hline$(\mathrm{m} / \mathrm{sec})$ & $1553.0 \pm 34.7$ & $1546.4 \pm 34.9$ & $1546.9 \pm 27.2$ & $1541.0 \pm 22.6$ \\
\hline
\end{tabular}

Table 5. SOS values according to walking speed.

\begin{tabular}{cccc}
\hline & Slowly & Natural & Fast \\
\hline SOS $(\mathrm{m} / \mathrm{sec})$ & 28 people & 131 people & 36 people \\
& $1550.6 \pm 33.6$ & $1545.6 \pm 32.4$ & $1561.4 \pm 36.1$ \\
\hline
\end{tabular}


Regarding the SOS according to the presence of current exercise or work, a significant difference was observed.

Regarding activity per day, we inquired about the proportion of time engaged in the following activities: 1) "Heavy exercise or labor"; 2) "Moderate exercise or labor"; 3) "Light exercise or labor"; 4) "Being in a sitting position"; and 5) "Complete rest or sleep". We set the points for each item as follows: a) (four points); b) (three points); c) (two points); d) (one point); and e) (0 points), and evaluated their activity level per day by multiplying time by the number of points. Table 7 shows the SOS according to the amount of activity per day, with an amount of activity less than 41 set as "Less", and more than 55 set as "More". The group with less activity included 39 people while the group with more activity included 64 people. Regarding the SOS according to the groups based on the amount of activity per day, a significant difference was observed.

Table 8 shows the SOS according to the presence of exercise experience in each period of elementary school, junior high school, and senior high school. During the elementary school years, the group with exercise experience included 147 people, whereas the group without included 48 people. Regarding the SOS according to the presence of exercise experience during the elementary school years, no significant difference was observed. During the junior high school years, the group with exercise experience included 137 people, whereas the group without included 58 people. Regarding the SOS according to the presence of exercise experience during the junior high school years, a significant difference was

Table 6. SOS values according to the presence of current exercise or work.

\begin{tabular}{ccc}
\hline & Presence & Absence \\
\hline SOS $(\mathrm{m} / \mathrm{sec})$ & 72 people & 123 people \\
& $1558.0 \pm 36.7$ & $1544.4 \pm 31.3$ \\
\hline
\end{tabular}

$\mathrm{p}<0.05$.

Table 7. SOS values according to the groups based on the amount of usual activity per day.

\begin{tabular}{cccc}
\hline & More & Normal & Less \\
\hline SOS $(\mathrm{m} / \mathrm{sec})$ & 61 people & 95 people & 39 people \\
& $1560.2 \pm 30.5^{*}$ & $1548.5 \pm 35.2$ & $1544.9 \pm 31.9$ \\
\hline
\end{tabular}

For the groups with normal and less activity, ${ }^{*} \mathrm{p}<0.05$.

Table 8. SOS values according to the presence of a history of past exercise.

\begin{tabular}{ccc}
\hline & Presence & Absence \\
\hline Elementary school & 147 people & 48 people \\
& $1549.0 \pm 33.9$ & $1551.1 \pm 33.6$ \\
Junior high school & 137 people & 58 people \\
& $1553.8 \pm 34.1^{*}$ & $1538.7 \pm 31.1$ \\
Senior high school & 98 people & 97 people \\
& $1557.4 \pm 37.7^{*}$ & $1541.3 \pm 27.8$ \\
\hline
\end{tabular}

For the group without, ${ }^{*} \mathrm{p}<0.01$. 
observed. During the senior high school years, the group with exercise experience included 98 people, whereas the group without included 97 people. Regarding the SOS according to the presence of exercise history during the senior high school years as well, a significant difference was observed.

Table 9 shows the SOS according to the presence of continuity of exercise in the elementary school, junior high school, and senior high school years. We compared the group with exercise experience throughout the elementary, junior high, and senior high school years with the group without continuity of exercise. The group with continuity of exercise throughout the elementary, junior high, and senior high school years included 71 people. Regarding the SOS according to the presence of continuity of exercise throughout the elementary, junior high, and senior high school years, a significant difference was observed. The group with continuity of exercise throughout the elementary and junior high school years included 42 people. Regarding the SOS according to the presence of continuity of exercise throughout the elementary and junior high school years, no significant difference was observed. The group with continuity of exercise throughout the junior high and senior high school years included 14 people. Regarding the SOS according to the presence of continuity of exercise throughout the junior high and senior high school years, a significant difference was observed.

We compared the group with exercise habits including volleyball or basketball, the group with exercise habits including other sports, and the group with no exercise habits. Table 10 shows the results according to elementary, junior high, and senior high school. Regarding the SOS according to the groups including those who had volleyball or basketball experience (40 people), those who had

Table 9. SOS values according to the presence of continuity of exercise.

\begin{tabular}{ccc}
\hline & Presence & Absence \\
\hline Continuity throughout the elementary, junior high, and & 71 people & 65 people \\
senior high school years & $1555.2 \pm 32.3^{\star}$ & $1539.6 \pm 31.6$ \\
Continuity throughout the elementary and junior high & 42 people & 65 people \\
school years & $1547.2 \pm 34.7$ & $1539.6 \pm 31.2$ \\
Continuity throughout the junior high and senior high & 14 people & 181 people \\
school years & $1575.4 \pm 36.7^{\star *}$ & $1539.6 \pm 29.8$
\end{tabular}

For the group without, ${ }^{*} \mathrm{p}<0.05,{ }^{* *} \mathrm{p}<0.01$

Table 10. SOS values according to the kinds of exercise (volleyball or basketball, others, nothing).

\begin{tabular}{cccc}
\hline & Volleyball or basketball & Others & Nothing \\
\hline \multirow{2}{*}{ Elementary school } & 40 people & 107 people & 48 people \\
& $1556.9 \pm 33.4$ & $1546.0 \pm 29.7$ & $1551.1 \pm 31.0$ \\
Junior high school & 40 people & 97 people & 58 people \\
& $1560.9 \pm 31.7^{\star}$ & $1551.0 \pm 30.5$ & $1538.7 \pm 32.4$ \\
Senior high school & 21 people & 78 people & 96 people \\
& $1568.0 \pm 36.1^{* *}$ & $1554.5 \pm 34.0$ & $1541.3 \pm 32.1$ \\
\hline
\end{tabular}

For the group without, ${ }^{\star} \mathrm{p}<0.01$; for the group with others and nothing, ${ }^{*} \mathrm{p}<0.01$. 
experience with other sports (107 people), and those who had no exercise experience (48 people) in the elementary school years, no significant difference was observed. Regarding the SOS of each group in the junior high school years, a significant difference between the group including those who had volleyball or basketball experience and the group with no exercise experience (58 people) was observed. Regarding the SOS according to the groups including those who had volleyball or basketball experience (21 people), those who had experience with other sports (78 people), and those who had no exercise experience (96 people) in the senior high school years, a significant difference was observed.

Regarding daily eating habits, we examined intake frequency by dividing it into three stages (less, normal, more). Table 11 shows the SOS values according to each food intake group. Those who had "less" overall food intake included 21 people, whereas those who had "more" overall food intake included 55 people. Regarding the SOS according to the groups of overall food intake, no significant difference was observed. Those who had "less" frequency eating milk and dairy products included 64 people, whereas those who had "more" included 64 people. Regarding the SOS according to the groups based on the frequency of milk and dairy product intake, no significant difference was observed. Those who had "less" frequency eating fish and small fish included 142 people, whereas those who had "more" included 10 people. Regarding the SOS according to the groups based on the frequency of fish and small fish intake, no significant difference was observed. Those who had "less" frequency eating bean and bean products included 109 people, whereas those who had "more" included 33 people. Regarding the SOS according to the groups based on the frequency of bean and bean product intake, a significant difference was observed. Those who had "less" frequency eating mushrooms included 114 people, whereas those who had "more"

Table 11. SOS values according to each food intake.

\begin{tabular}{cccc}
\hline & More & Normal & Less \\
\hline Overall food intake & 55 people & 119 people & 21 people \\
Milk & $1548.8 \pm 35.9$ & $1549.8 \pm 34.7$ & $1542.1 \pm 26.4$ \\
& 64 people & 67 people & 64 people \\
Small fish & $1550.9 \pm 30.8$ & $1551.6 \pm 34.1$ & $1544.8 \pm 37.9$ \\
& 10 people & 43 people & 142 people \\
Bean & $1538.7 \pm 24.2$ & $1549.8 \pm 30.0$ & $1550.0 \pm 35.8$ \\
& 33 people & 53 people & 109 people \\
Mushroom & $1561.3 \pm 29.9^{*}$ & $1551.2 \pm 34.7$ & $1545.7 \pm 34.8$ \\
& 22 people & 59 people & 114 people \\
Green and yellow vegetables & $1551.3 \pm 31.2$ & $1555.6 \pm 37.2$ & $1546.6 \pm 33.2$ \\
& 33 people & 100 people & 62 people \\
Seaweed & $1562.5 \pm 32.0^{*}$ & $1548.3 \pm 37.1$ & $1544.5 \pm 29.2$ \\
& 10 people & 66 people & 119 people \\
\hline & $1542.6 \pm 33.8$ & $1540.1 \pm 27.3$ & $1553.8 \pm 36.6$
\end{tabular}

For the group with less intake, ${ }^{\star} \mathrm{p}<0.01$ 
included 22 people. Regarding the SOS according to the groups based on the frequency of mushroom intake, no significant difference was observed. Those who had "less" frequency eating green and yellow vegetables included 62 people, whereas those who had "more" included 33 people. Regarding the SOS according to the groups based on the frequency of green and yellow vegetable intake, a significant difference was observed. Those who had "less" frequency eating seaweed included 119 people, whereas those who had "more" included 10 people. Regarding the SOS according to the groups based on the frequency of seaweed intake, no significant difference was observed. Those who had "less" frequency eating pork included 49 people, whereas those who had "more" included 55 people. Regarding the SOS according to the groups based on the frequency of pork intake, no significant difference was observed.

\section{Discussion}

In this study, we examined the relationship between bone density and physical attributes or lifestyle of female students along with factors which impacted bone density.

In this survey, no significant correlation between height, weight, BMI, or body fat percent and the SOS value was observed. Preceding studies reported a relationship between bone mass and BMI among female university students and adult females [7] [8], with weight believed to be a factor enhancing bone density due to the load placed on the bones as well as exercise particularly in the direction of gravity. Although the reasons for disagreement with the results from this study were unclear, the subjects might have been a group in which the impact of exercise was greater than that of weight.

The group with bone fracture experience indicated higher bone density values. This is believed to have occurred due to intense exercise because those in the group with bone fracture experience included many people who had exercise experience. Regarding the presence of a history of osteoporosis diagnosis in a family member (parent, brother or sister, grandparent), although there was a tendency for those having a history of osteoporosis diagnosis in their family to indicate relatively low values, it was not concluded to be a significant difference. As the heritability of bone density is $40 \%$ to $70 \%$, it is said that the correlation among family members is high and the impact of heredity is great [9] [10]. However, genetic factors may be surmounted by being exposed to certain lifestyles as an external factor.

Regarding the walking time per day and walking speed, no significant difference was observed. Although we were unable to observe a relationship between walking and bone density in this study targeting young people in their teens and twenties, it has been reported that light dynamic load exercises such as walking among those in menopause significantly raise the bone density of the lumbar spine [11]. Among young people, although walking only rarely has a significant impact on the increase in bone density, it may become effective in controlling the decrease in bone density in the future. 
Subjects with a history of exercise included 147 people $(75.4 \%)$ in the elementary school years, 137 people $(70.3 \%)$ in the junior high school years, and 98 people $(50.3 \%)$ in the senior high school years. Although there were differences in the kinds of exercise as well as the frequency thereof, more than half of the subjects had a history of exercise in the past. Looking at the relationship between exercise history and bone density, those having a history of exercise generally had higher bone density. Specifically, our results indicated that while no relationship exists between exercise habits and bone density in the elementary school years, exercise habits during the junior high and high school years had a great impact on the acquisition of peak bone mass. Preceding studies also reported that having exercise habits during the junior high school and high school years was an important factor in increasing bone density [12]. This survey also indicated results supporting this. Furthermore, because the bone density among students who had continued to exercise throughout the junior high and senior high school years indicated high values, it was clarified that a certain period of continuity of exercise habits during the growth period (adolescence) had a great impact on peak bone mass.

Looking at bone density in terms of the kinds of exercise, the bone density among those who had volleyball or basketball experience indicated high values. Even among all forms of exercise, volleyball and basketball are referred to as sports in which loads are applied to bones, with many reports supporting the fact that bone density among those engaging in volleyball is particularly high compared with other kinds of sports [13] [14]. In volleyball and basketball, movements such as jumping and landing as well as movements including sprinting are repeatedly performed. Because a large load is applied to bones at the time of such movements, although the mechanism is unclear, it is believed to be effective in increasing bone density [6] [12]. In this study, the results suggested that those with volleyball or basketball experience particularly in the senior high school years exhibited significantly high bone density compared with others. Omasu et al. [8] stated that the amount of physical activity in the senior high school years had an impact on bone mass. As load is categorized as a qualitative issue and the amount of physical activity is categorized as a quantitative issue, both may have a significant impact on the growth period. As a quantitative aspect, because the amount of physical activity during the senior high school years is greater than that of the elementary school and junior high school years, at this point it is believed to play a role in the acquisition of high bone density.

Several limitations associated with the present study warrant mention. First, the number of subjects was small. Second, the questionnaire used in this study is one that addresses self-perceived bone health. As such, the precise calcium intake of the subjects was not investigated in this study. Among the subjects in this survey, few subjects ate a lot of food which is supposed to have a positive impact on the bones. This is inferred to be because many of the subjects were university students who left their home and lived on their own. Before becoming senior high school students, guidance on eating habits for families is believed to be es- 
sential, and during the senior high school years, guidance on eating habits after students leave home is believed to be essential. Regarding the content of meals, foods observed to have a relationship with bone density included "bean and bean products" and "green and yellow vegetables". Both foods include many varieties which are rich in vitamins and minerals, ingredients having a positive impact on the bones. Although there are many unclear points regarding these biochemical mechanisms, it has been reported that beans inhibit the decrease in bone mass of model rats with osteoporosis [15] while green and yellow vegetables have a positive impact on the bones [16]. It was interesting to note that ingredient factors which were expected to have a relationship with bones were raised from a simple nutrition survey as in this study. Going forward, first, we hope to examine the extent of the impact that these foods have on the bones in detail via a large-scale cohort study focusing on nutritional ingredients.

From the perspective of osteoporosis prevention, it is hard to believe that recognition by coaches is sufficient. Regarding the significance of osteoporosis prevention in one's youth, it is necessary for families and schools to deepen recognition both at home and at school. Providing guidance on the importance of osteoporosis prevention in one's youth is believed to be important by informing families that exercise habits and eating habits in one's youth have a great impact on maximum bone density for life via a health bulletin, etc. Moreover, from the perspective of not only osteoporosis prevention but also lifestyle diseases prevention, enhancing health education, including holding nutrition classes, is also believed to be important. While the need for health education during the school years and at puberty is increasing, coming up with a way of providing effective guidance based on the actual situation of children is raised as a topic for future discussion.

\section{References}

[1] Sandström, L., McGuigan, F.E., Callréus, M. and Akesson, K.E. (2016) Peak Bone Mass and Quantitative Ultrasound Bone Properties in Young Adulthood: A Study in the PEAK-25 Cohort of Women. Journal of Clinical Densitometry, 19, 477-484.

[2] Kyvernitakis, I., Kostev, K., Nassour, T., Thomasius, F. and Hadji, P. (2017) The Impact of Depot Medroxyprogesterone Acetate on Fracture Risk: A Case-Control Study from the UK. Osteoporosis International, 28, 291-297.

https://doi.org/10.1007/s00198-016-3714-4

[3] Kim, S., So, W.Y., Kim, J. and Sung, D.J. (2016) Relationship between Bone-Specific Physical Activity Scores and Measures for Body Composition and Bone Mineral Density in Healthy Young College Women. PLoS ONE, 11, e0162127. https://doi.org/10.1371/journal.pone.0162127

[4] Gaffney-Stomberg, E., Lutz, L.J., Rood, J.C., Cable, S.J., Pasiakos, S.M., Young, A.J. and McClung, J.P. (2014) Calcium and Vitamin D Supplementation Maintains Parathyroid Hormone and Improves Bone Density during Initial Military Training: A Randomized, Double-Blind, Placebo Controlled Trial. Bone, 68, 46-56.

[5] Omasu, F. and Hayashi, M. (2013) The Effect of Perceived Body Shapes on the Desire to Bethin in Fifth and Sixth Graders in Elementary School. Asian Pacific Journal of Disease Management, 7, 25-33. https://doi.org/10.7223/apjdm.7.25 
[6] Mosti, M.P., Carlsen, T., Aas, E., Hoff, J., Stunes, A.K. and Syversen, U. (2014) Maximal Strength Training Improves Bone Mineral Density and Neuromuscular Performance in Young Adult Women. The Journal of Strength \& Conditioning Research, 28, 2935-2945. https://doi.org/10.1519/JSC.0000000000000493

[7] Omasu, F., Kitagawa, J., Koyama, K., Asakawa, K., Yokouchi, J., Ando, D. and Nakahara, Y. (2004) The Influence of VDR Genotype and Exercise on Ultrasound Parameters in Young Adult Japanese Women. Journal of Physiological Anthropology, 23, 49-55. https://doi.org/10.2114/jpa.23.49

[8] Omasu, F., Seki, Y., Hashiguchi, S.U., Hashiguchi, S.H., Yamakami, K., Sakurai, Y. and Nakahara, Y. (2011) The Influence of Physical Activity on the Bone Mass through the Bone Metabolism in Premenopausal Adult Japanese Women. Journal of Public Health, 19, 241-247. https://doi.org/10.1007/s10389-011-0394-6

[9] Pocock, N.A., Eisman, J.A., Hopper, J.L., Yeates, M.G., Sambrook, P.N. and Eberl, S. (1987) Genetic Determinants of Bone Mass in Adults. The Journal of Clinical Investigation, 80, 706-710. https://doi.org/10.1172/JCI113125

[10] Krall, E.A. and Dawson-Hughes, B. (1993) Heritable and Life-Style Determinants of Bone Mineral Density. Journal of Bone and Mineral Research, 8, 1-9. https://doi.org/10.1002/jbmr.5650080102

[11] Kitagawa, J., Omasu, F. and Nakahara, Y. (2003) Effect of Daily Walking Steps on Ultrasound Parameters of the Calcaneus in Elderly Japanese Women. Osteoporosis International, 14, 219-224. https://doi.org/10.1007/s00198-002-1339-2

[12] Omasu, F., Kitagawa, J., Koyama, K., Tanaka, M., Asakawa, K. and Nakahara, Y. (2002) The Relation of Calcaneal Ultrasound Bone Parameter to Physicalactivity in Japanese Adult Females. Osteoporosis Japan, 10, 99-108.

[13] Lehtonen-Veromaa, M., Mottonen, T., Nuotio, I., Heinonen, O.J. and Viikari, J. (2000) Influence of Physical Activity on Ultrasound and Dualenergy X-Ray Absorptiometry Bone Measurements in Peripubertalgirls: A Cross-Sectional Study. Calcified Tissue International, 66, 248-254. https://doi.org/10.1007/s002230010050

[14] Alfredson, H., Nordstrom, P. and Lorentzon, R. (1997) Bone Mass in Female Volleyball Players: A Comparison of Total and Regional Bone Mass in Female Volleyball Players and Nonactive Females. Calcified Tissue International, 60, 338-342. https://doi.org/10.1007/s002239900239

[15] Byun, J.S. and Lee, S.S. (2010) Effect of Soybeans and Sword Beans on Bone Metabolism in a Rat Model of Osteoporosis. Annals of Nutrition and Metabolism, 56, 106-112. https://doi.org/10.1159/000277663

[16] Wosje, K.S., Khoury, P.R., Claytor, R.P., Copeland, K.A., Hornung, R.W., Daniels, S.R. and Kalkwarf, H.J. (2010) Dietary Patterns Associated with Fat and Bone Mass in Young Children. The American Journal of Clinical Nutrition, 92, 294-303. https://doi.org/10.3945/ajen.2009.28925 
Submit or recommend next manuscript to SCIRP and we will provide best service for you:

Accepting pre-submission inquiries through Email, Facebook, LinkedIn, Twitter, etc. A wide selection of journals (inclusive of 9 subjects, more than 200 journals)

Providing 24-hour high-quality service

User-friendly online submission system

Fair and swift peer-review system

Efficient typesetting and proofreading procedure

Display of the result of downloads and visits, as well as the number of cited articles Maximum dissemination of your research work

Submit your manuscript at: http://papersubmission.scirp.org/

Or contact ojpm@scirp.org 